\title{
C1-esterase inhibitor treatment: preclinical safety aspects on the potential prothrombotic risk
}

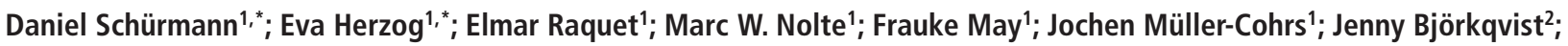 \\ Gerhard Dickneite'; Ingo Pragst ${ }^{1}$ \\ ${ }^{1} \mathrm{CSL}$ Behring GmbH, Marburg, Germany; ${ }^{2}$ Department of Molecular Medicine and Surgery, and Center of Molecular Medicine, Karolinska Institutet, Stockholm, Sweden
}

\begin{abstract}
Summary
Human plasma-derived C1-esterase inhibitor (C1-INH) is an efficacious and safe treatment for hereditary angioedema. However, thrombotic events in subjects treated with $\mathrm{C1}-\mathrm{INH}$ at recommended or offlabel, high doses have been reported. In this study, we addressed the potential prothrombotic risk of C1-INH treatment in high doses using a non-clinical rabbit model. Following intravenous infusion of $\mathrm{C1} 1 \mathrm{INH}$ to rabbits at doses up to $800 \mathrm{IU} / \mathrm{kg}$, the exposure and the pharmacodynamic efficacy of C1-INH in rabbits were confirmed by activity measurements of $\mathrm{C1}$-esterase, and coagulation factors Xla and XIla, respectively. Potential prothrombotic effects were assessed following induction of venous and arterial thrombosis using in vivo models of venous and arterial stasis, complemented by various in vitro assays of coagulation markers. Administration of $\mathrm{C1}-\mathrm{INH}$ at doses up to $800 \mathrm{IU/}$ $\mathrm{kg}$ did not potentiate thrombus formation during venous stasis. In contrast, inhibition of arterial occlusion was observed upon C1-INH
\end{abstract}

Correspondence to:

Dr. Ingo Pragst

CSL Behring GmbH, Marburg

Emil-von-Behring Straße 76, 35041 Marburg, Germany

Tel.: +49 642139 2799, Fax: +496421 395310

E-mail: Ingo.Pragst@cslbehring.com

Equal contribution. administration when compared with isotonic saline treatment, indicating antithrombotic rather than prothrombotic activity of high dose C1-INH treatment in vivo. This was further confirmed in vitro by decreased thrombin generation, increased activated partial thromboplastin time, clotting time and clot formation time, and inhibition of platelet aggregation. No relevant changes in fibrinolysis or in the levels of thrombin-antithrombin complexes, and prothrombin fragment $1+2$ were observed upon high dose C1-INH treatment. The data suggest that treatment of healthy rabbits with high doses of C1-INH could potentially inhibit coagulation and thrombus formation rather than induce a prothrombotic risk.

\section{Keywords}

Animal model, C1-esterase inhibitor, coagulation, contact activation system, thrombosis

Financial support:

This work was funded by CSL Behring GmbH.

Received: June 10, 2013

Accepted after major revision: June 16, 2014

Epub ahead of print: August 7, 2014

http://dx.doi.org/10.1160/TH13-06-0469

Thromb Haemost 2014; 112: 960-971

\section{Introduction}

C1-esterase inhibitor (C1-INH), a plasma glycoprotein with a molecular weight of $104 \mathrm{kDa}$, belongs to the protein family of serine protease inhibitors (serpins) which regulate the activity of serine proteases by inhibiting their catalytic activity (1). As the only known inhibitor of the activated serine proteases $\mathrm{C} 1 \mathrm{~s}$ and $\mathrm{Clr}$, C1-INH inhibits the classical pathway of the complement system. Furthermore, C1-INH is a major inhibitor of the contact activation system due to its ability to inhibit the activated serine proteases factor XIIa (FXIIa), factor XIa (FXIa), and plasma kallikrein $(2,3)$. Deficiency in C1-INH leads to the clinical manifestation of hereditary angioedema (HAE), which is characterised by episodes of acute angioedema attacks in subcutaneous or submucosal tissues such as the skin, larynx, or visceral organs (4). Subtypes of HAE are characterised by genetically reduced synthesis of C1-INH (type I), functional deficiency of C1-INH (type II), or FXII mutations (type III), resulting in increased bradykinin release upon stimulation of the contact activation system (5). HAE attacks can be treated effectively by administering exogenous C1-INH (4, 5). Due to its inhibitory effects on the complement and the contact activation systems, C1-INH substitution restores normal haemostatic function and inhibits the excessive formation of vasoactive peptides such as bradykinin, which mediate the formation of angioedema.

Even though treatment with C1-INH purified from pooled human plasma has been demonstrated to be safe for many years $(6,7)$, there have been recent reports suggesting increased risk of thromboembolic complications associated with the use of C1-INH $(8,9)$, particularly beyond the approved clinical indications and doses. During off-label administration of C1-INH to neonates and infants undergoing cardiopulmonary bypass surgery at doses up to $500 \mathrm{IU} / \mathrm{kg}$, i.e. 25 times higher than recommended for HAE patients, to prevent capillary leakage, occasionally lethal thromboembolic complications in the upper venous system were observed. These adverse events were believed to be at least partly associated with C1-INH treatment due to its inhibitory effects on the fibrinolytic system $(6,10)$. However, it should be noted that the 
induction of thrombosis in neonates under surgery is highly complex. Central venous lines, surgically traumatised vessels, alteration of coagulation by extracorporeal circulation, and the immature haemostatic system of the newborn could considerably contribute to a thrombotic risk.

Horstick et al. (11) examined the cardioprotective effects of C1-INH using a pig model of coronary artery occlusion and reperfusion, and reported protective effects of C1-INH at low doses $(<100 \mathrm{IU} / \mathrm{kg})$. However, adverse effects were observed at higher doses ( $\geq 100 \mathrm{IU} / \mathrm{kg}$ ), including clot formation (inhibiting blood aspiration from non-heparinised intravenous [i.v.] catheters) and increased thrombin-antithrombin (TAT) levels. Another investigation into the potential thrombogenicity of a $\mathrm{C} 1-\mathrm{INH}$ product using a rabbit stasis model for venous thrombosis concluded that $\mathrm{C} 1-\mathrm{INH}$ presents a thrombogenic risk with a threshold of between 100 and $200 \mathrm{IU} / \mathrm{kg}$ and a non-observed adverse effect level (NOAEL) of $\leq 50 \mathrm{IU} / \mathrm{kg}$ (12). In contrast, Tassani et al. (13) demonstrated a clinical benefit of administering C1-INH at a dose of $100 \mathrm{IU} / \mathrm{kg}$ in neonates undergoing arterial switch operations.

A recent retrospective data analysis based on reports from the United States Food and Drug Administration's Adverse Event Reporting System database resulted in 10 confirmed cases of C1-INH product-associated thrombotic events in HAE patients using recommended doses (14). However, the analysis did not allow any causal relationship between the investigated drug treatment and adverse events to be established. Despite the possibility that the thrombotic events associated with the specific C1-INH product may be related to the use of catheters or underlying risk factors (9), further studies on the potential risk associated with C1-INH treatment are warranted.

To support the safety of a recombinant C1-INH product, Relan et al. (15) evaluated the effects of C1-INH treatment on coagulation and fibrinolysis in a randomised clinical trial in symptomatic HAE patients. Infusion of the recombinant C1-INH did not affect parameters reflecting activation of the coagulation and fibrinolytic systems, such as levels of TAT, D-dimers, or plasmin-antiplasmin (PAP) complexes, with the exception of the activated partial thromboplastin time (aPTT), which was prolonged, and of prothrombin fragment $1+2(\mathrm{~F} 1+2)$ levels, which were decreased. However, the baseline levels of F1+2, TAT, D-dimers, and PAP complexes were already elevated, and aPTT was low to normal in the majority of these patients prior to recombinant C1-INH treatment, indicating activation of both coagulation and fibrinolysis in HAE patients. These data are supported by observations by Cugno et al. (16), who had previously suggested activation of the coagulation cascade in HAE patients during attacks. Overall, Relan et al. (15) observed no thromboembolic events in HAE patients following recombinant C1-INH treatment at doses up to $100 \mathrm{IU} / \mathrm{kg}$.

Interestingly, antithrombotic effects were observed in a murine model of ischaemic stroke upon C1-INH treatment (17), as well as in several preclinical thrombosis models, upon inhibition $(18,19)$ or genetic deletion $(20,21)$ of C1-INH target molecules, i.e. FXII and FXI.

Against this background, we conducted a preclinical study designed to complement previous investigations and to provide further insight into the effects of $\mathrm{C} 1-\mathrm{INH}$ on the coagulation system, as well as to further assess the risk of thrombotic complications following administration of high doses of human plasmaderived $\mathrm{C} 1-\mathrm{INH}$.

\section{Materials and methods}

Additional details of the methods are included in the Supplementary Material (available online at www.thrombosis-online.com).

\section{Animals and anaesthesia}

Three to 4 months old Chinchilla Bastard (CHB) or New Zealand White (NZW) rabbits were used. Except for plasma sampling for pharmacokinetic analysis, all treatments were conducted upon anaesthesia induced by ketamine and xylazine.

\section{Activity of C1-esterase and coagulation FXIa and FXIla}

Purified C1-INH obtained from pooled human plasma (Berinert, CSL Behring, Marburg, Germany) was injected i.v. at a dose of 200 $\mathrm{IU} / \mathrm{kg}$ to $\mathrm{CHB}$ rabbits, and blood samples were collected at different time points. C1-INH activity levels were analysed based on the inhibition of human C1-esterase activity (Berichrom C1-Inhibitor, Siemens Healthcare Diagnostics Products, Marburg, Germany). Using the same method, $\mathrm{C} 1-\mathrm{INH}$ activity was determined following i.v. infusion of cumulative doses of 100, 400, and $800 \mathrm{IU} /$ $\mathrm{kg} \mathrm{C} 1-\mathrm{INH}$ or equal volumes of isotonic saline $(0.9 \%$ sodium chloride) to $\mathrm{CHB}$ rabbits.

The activity of FXIa or FXIIa was assessed in plasma from CHB rabbits treated with cumulative doses of $\mathrm{C} 1-\mathrm{INH}$ or equal volumes of isotonic saline, based on aPTT measurement using the BCS ${ }^{\circ} \mathrm{XP}$ system (Siemens Healthcare Diagnostics Products).

\section{Comparison of effects of C1-INH on coagulation in rabbit and human plasma in vitro}

C1-INH efficacy was assessed, following addition of 10, 15, 20, 40, 60 , and $80 \mathrm{IU} / \mathrm{ml} \mathrm{C1-INH}$ or equal volumes of saline into rabbit plasma or standard human plasma (SHP), based on measurements of FXIa and FXIIa activity, aPTT and PT using the BCS XP system (Siemens Healthcare Diagnostics Products).

\section{Venous and arterial thrombosis}

\section{In vivo models of venous thrombosis}

Venous thrombosis was investigated in NZW rabbits using the Wessler model (22) modified by Giles et al. (23). Venous stasis was induced for $30 \mathrm{~min}$ following single i.v. administrations of isotonic saline, Feiba NF 500 E (Factor Eight Inhibitor Bypassing Activity, Baxter, Unterschleissheim, Germany) at doses of 5, 10, 25, 50, or $100 \mathrm{IU} / \mathrm{kg}$ and $\mathrm{C} 1-\mathrm{INH}$ at doses of 200, 400, and $800 \mathrm{IU} / \mathrm{kg}$. 
Thrombus score and thrombus wet weight were assessed, as described in the Supplementary Material (available online at www. thrombosis-online.com).

Thrombus wet weight was also assessed after 3 hours (h) of venous stasis which was induced at the end of the administration of C1-INH cumulative doses $(100,400$, and 800 IU/kg) or equal vol-

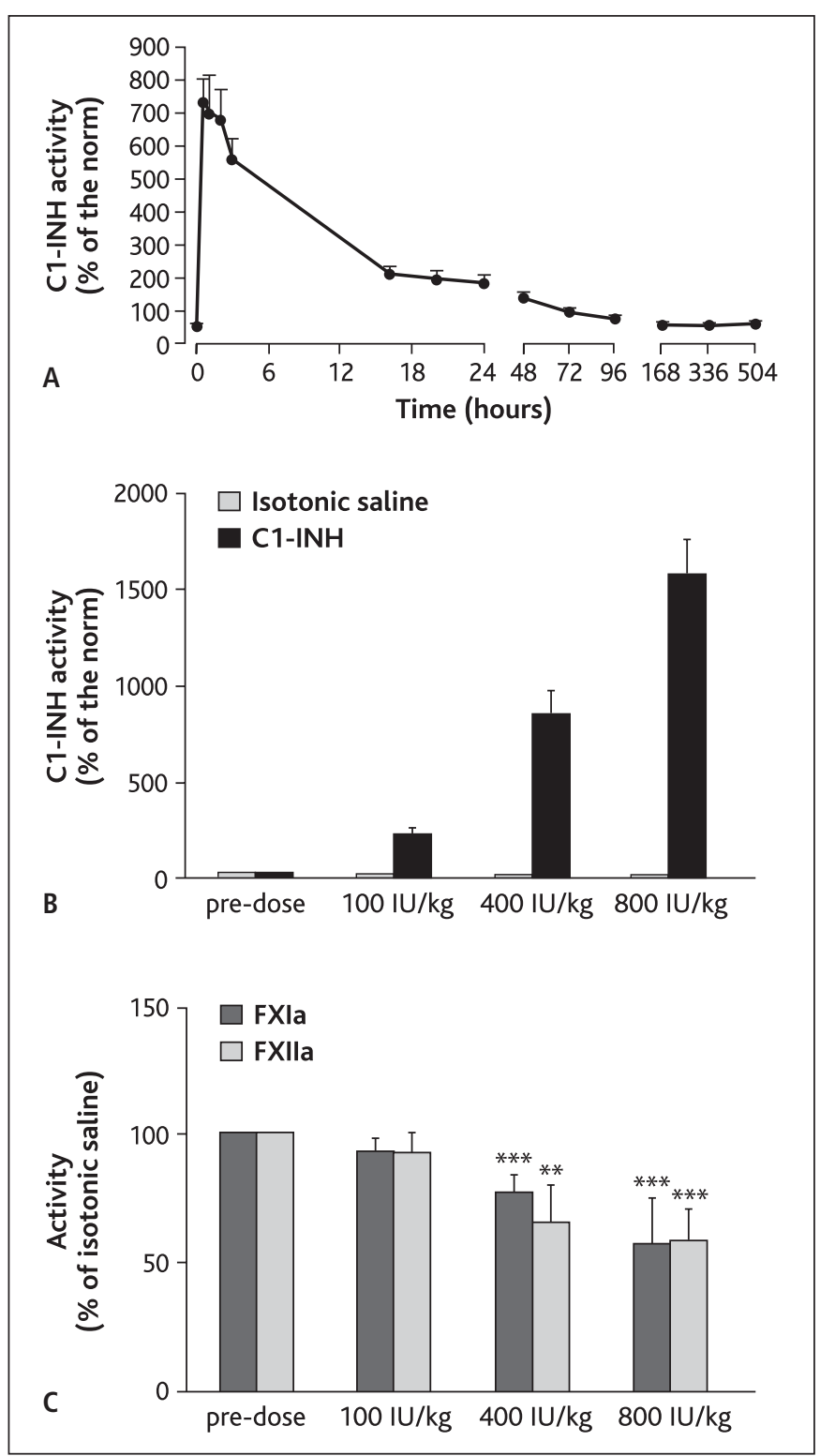

Figure 1: Pharmacokinetic and pharmacodynamic properties of C1-esterase inhibitor (C1-INH) in rabbits. C1-INH activity was assessed by measuring the inhibition of $\mathrm{C} 1$-esterase activity $(\mathrm{A})$, at various time points upon administration of $200 \mathrm{IU} / \mathrm{kg} \mathrm{C1-INH}$ and (B) upon administration of cumulative doses of $\mathrm{C} 1$-INH or equal volumes of isotonic saline. Values are expressed as percentage of C1-INH activity in standard human plasma (norm). C) Coagulation factors Xla (FXIa) and XIla (FXIla) activity levels were measured in rabbit plasma following administration of cumulative doses of C1-INH or equal volumes of isotonic saline. C1-INH values were normalised to pre-dose and corresponding isotonic saline values. For A-C: Dots and bars show means \pm SD. ${ }^{* *} \mathrm{P}=0.0024,{ }^{* *} \mathrm{P}<0.0001$. umes of isotonic saline. Prior to each infusion and after the last infusion, blood samples were drawn for analysis of coagulation markers (see "In vitro coagulation assays").

\section{In vivo model of arterial thrombosis}

C1-INH $(800 \mathrm{IU} / \mathrm{kg})$ or an equal volume of isotonic saline were infused to $\mathrm{CHB}$ rabbits. Thereafter, arterial thrombosis was induced using a modification of the method originally described by Reimann-Hunziger (24) and Kurz et al. (25). Shortly, both femoral arteries were treated with $70 \%$ ferric chloride $\left(\mathrm{FeCl}_{3}\right)$ for $60 \mathrm{~min}$ utes (min) while arterial occlusion was assessed for up to $90 \mathrm{~min}$, using a flow module TS420 and perivascular flow probes (Transonic Systems Inc., Ithaca, NY, USA).

\section{In vitro coagulation assays}

The assessment of coagulation by in vitro assays was performed following either i.v. treatment of $\mathrm{CHB}$ rabbits at cumulative doses of C1-INH (100, 400, and $800 \mathrm{IU} / \mathrm{kg})$ or equal volumes of isotonic saline, as described in "In vivo models of venous thrombosis" or addition of C1-INH to rabbit plasma, SHP, or washed platelets derived from rabbit whole blood.

\section{Thrombus formation and fibrinolysis using thromboelastography}

Overall clot formation was assessed by determination of thromboelastographic parameters (clot formation time [CFT], clotting time [CT], maximum clot firmness [MCF]) using the Rotem 05 system (Tem International, Munich, Germany). Coagulation of citrated whole blood from $\mathrm{Cl}-\mathrm{INH}$ or isotonic saline treated $\mathrm{CHB}$ rabbits was activated by use of INTEM, EXTEM, or NATEM.

Fibrinolysis was induced by addition of tissue plasminogen activator (tPA) $(0.1 \mu \mathrm{g} / \mathrm{ml}$; Actilyse, Boehringer Ingelheim, Biberach, Germany) to rabbit whole blood from C1-INH or isotonic saline treated CHB rabbits, followed by addition of EXTEM; the lysis index 60 (LI60) was measured.

\section{Platelet aggregation}

Platelets were activated within heparinised whole blood $(5 \mathrm{IU} / \mathrm{ml}$ heparin; Ratiopharm, Ulm, Germany) from CHB rabbits treated with $\mathrm{C} 1-\mathrm{INH}$ or isotonic saline, by addition of either collagen (COLtest, $100 \mu \mathrm{g} / \mathrm{ml}$ ) or adenosine diphosphate (ADP) (ADPtest, $0.2 \mathrm{mM}$ ). Platelet aggregation was assessed using impedance aggregometry (Multiplate Analyzer 5.0, Instrumentation Laboratory, Munich, Germany).

In addition, washed platelets were spiked with $\mathrm{C} 1-\mathrm{INH}$ at concentrations of $3.125 \mathrm{IU} / \mathrm{ml}$ to $50 \mathrm{IU} / \mathrm{ml}$ (reflecting C1-INH plasma levels following i.v. doses of approximately 100 to $1,600 \mathrm{IU} / \mathrm{kg}$ ) $(n=2)$. Platelet aggregation was then measured using the APACT 4 system (Rolf Greiner BioChemica, Flacht, Germany) following activation with rabbit thrombin $(0.1 \mathrm{IU} / \mathrm{ml}$; Sigma Aldrich, Munich, Germany). 


\section{Activated partial thromboplastin time and prothrombint ime}

Blood samples were drawn from $\mathrm{CHB}$ rabbits treated with $\mathrm{C} 1-\mathrm{INH}$ or isotonic saline. APTT was determined following intrinsic activation, and prothrombin time (PT) was determined, following extrinsic activation, using the $\mathrm{BCS}^{\circ} \mathrm{XP}$ analyser (Siemens Healthcare Diagnostics Products).

\section{Thrombin generation}

The thrombin generation assay (TGA) was conducted using calibrated thrombinography (Thrombinoscope, Maastricht, the Netherlands) in plasma samples from the $\mathrm{C} 1-\mathrm{INH}$ or isotonic saline treated animals, upon intrinsic or extrinsic activation. The thrombin calibrated automated thrombograms ( $\mathrm{dF} / \mathrm{dt}$ vs time) were used to determine the TGA parameters: peak thrombin levels, lag-time, and endogenous thrombin potential (ETP).

\section{Thrombin-antithrombin complexes}

TAT complexes were determined in blood samples drawn from $\mathrm{CHB}$ rabbits treated with $\mathrm{C} 1-\mathrm{INH}$ or isotonic saline, using a TAT enzyme-linked immunosorbent assay (ELISA) kit (Cusabio Biotech, Wuhan, China) according to the manufacturer's instructions.

In addition, TAT complexes were determined in plasma samples obtained during the assessment of arterial thrombosis as described in "In vivo model of arterial thrombosis".

\section{Prothrombin fragment $1+2$}

F1+2 levels were determined in plasma samples obtained during the assessment of arterial thrombosis as described in "In vivo model of arterial thrombosis", using a F1+2 ELISA Kit (Cusabio), according to the manufacturer's instructions.

\section{Statistical analysis and data presentation}

Data from each dose of C1-INH were compared with corresponding data from the control group, using test statistics for two independent samples. Pre-dose data were accounted for by using analysis of covariance models, if possible. In that case, the estimated treatment effects were derived from the statistical model. P-values below 0.05 were termed statistically significant. Details on the statistical analysis can be found in the Supplementary Material (available online at www.thrombosis-online.com).

\section{Results}

\section{Evaluation of the pharmacokinetic and pharmaco- dynamic properties of C1-INH in rabbits}

The pharmacological activity of plasma-derived human C1-INH was compared between rabbit and human, based on the inhibition of FXIa and FXIIa activities, as well as aPTT and PT measure-

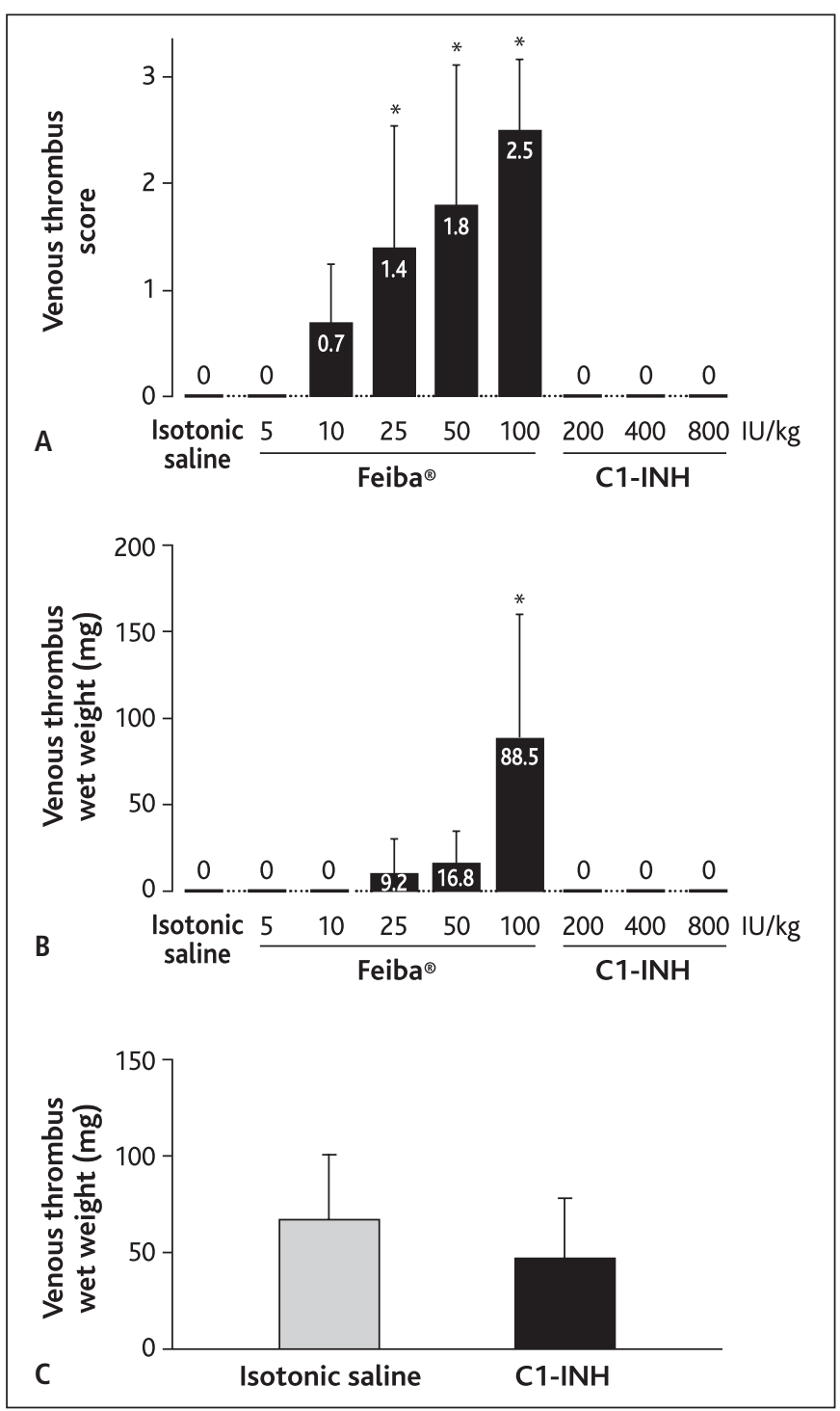

Figure 2: Effects of C1-esterase inhibitor (C1-INH) on venous thrombosis in rabbits in vivo. Thrombus score (A) and thrombus wet weight (B) were measured following single administrations of isotonic saline, Feiba ${ }^{\circledR}$, or $\mathrm{C} 1-\mathrm{INH}$ and 30 min of venous stasis. Bars show means \pm SD. ${ }^{*} \mathrm{P}<0.05$. C) Thrombus wet weight was measured following $3 \mathrm{~h}$ of venous stasis in rabbits treated with cumulative doses of C1-INH up to $800 \mathrm{IU} / \mathrm{kg}$ or equal volumes of isotonic saline. Bars show means \pm SD.

ments in vitro. To this end, rabbit plasma or SHP were spiked with increasing concentrations of $\mathrm{C} 1-\mathrm{INH}$, which correspond to in vivo exposures of 400 to $800 \mathrm{IU} / \mathrm{kg}$ and above. Similar concentrationdependent effects of C1-INH on FXIIa inhibition between rabbitand human-derived plasma were observed (Suppl. Figure 1A, available online at www.thrombosis-online.com), while C1-INH mediated FXIa inhibition was stronger in human plasma compared to rabbit plasma (Suppl. Figure 1B, available online at www. thrombosis-online.com), indicating that the pharmacodynamics of C1-INH were at least partially comparable between rabbits and humans. Interestingly, in this assay, in rabbit plasma a 1.49-fold higher FXII- and a 3.8-fold higher baseline FXI activity compared 
to human plasma were found (data not shown) which is in line with Karges et al. (26). Additionally, aPTT and PT were analysed in rabbit- and human-derived plasma. As expected, no influence of C1-INH on PT was found whereas rabbit aPTT was even stronger affected by increasing concentrations of C1-INH compared to human aPTT values (Suppl. Figure 1C-D, available online at www.thrombosis-online.com). Furthermore, efficacy of C1-INH regarding the inhibition of human and rabbit contact system activation was demonstrated via Western blotting of high-molecular weight kininogen (HMWK) cleavage (Suppl. Figure 2, available online at www.thrombosis-online.com). Here, a similar dose-response in the inhibition of HMWK cleavage upon activation of the kallikrein-kinin system was found in both rabbit and human plasma following addition of C1-INH in vitro. These data clearly demonstrate the pharmacological activity of C1-INH in rabbit plasma.

The assessment of the in vivo exposure and pharmacokinetic behaviour of plasma-derived human C1-INH in rabbits was based on measurements of C1-esterase inhibition.

Following i.v. administration of a single dose of $200 \mathrm{IU} / \mathrm{kg}$, an initial rise in C1-INH activity to $737 \%$ of endogenous normal (SHP) levels was measured, corresponding to a 14-fold increase from baseline ( Figure 1A). Maximum C1-INH activity levels dropped by $8 \%$ and $24 \%$, at $2 \mathrm{~h}$ and $3 \mathrm{~h}$ post-dose, respectively, and reached baseline levels after $168 \mathrm{~h}$ (Day 7). In addition, a terminal half-life of $1.4 \pm 0.2$ days, an overall exposure (area under the curve $[\mathrm{AUC}])$ of $6.3 \pm 0.8$ day $\times \mathrm{IU} / \mathrm{ml}$ and clearance of $39 \pm 4$ $\mathrm{ml} / \mathrm{kg} /$ day were determined (means \pm standard deviation [SD]).

Cumulative doses of $100 \mathrm{IU} / \mathrm{kg}$ ( 0 to $5 \mathrm{~min}$ ), $400 \mathrm{IU} / \mathrm{kg}$ (5 to 15 $\mathrm{min}$ ), and $800 \mathrm{IU} / \mathrm{kg}$ (15 to $30 \mathrm{~min}$ ) of C1-INH resulted in a dosedependent increase in C1-INH activity ranging between $238 \pm$ $31 \%$ and $1587 \pm 184 \%$ of endogenous normal levels at 100 and $800 \mathrm{IU} / \mathrm{kg}$ compared with $32 \pm 7 \%$ at pre-dose (means \pm SD; - Figure 1B). At the highest dose level tested, this translates to a

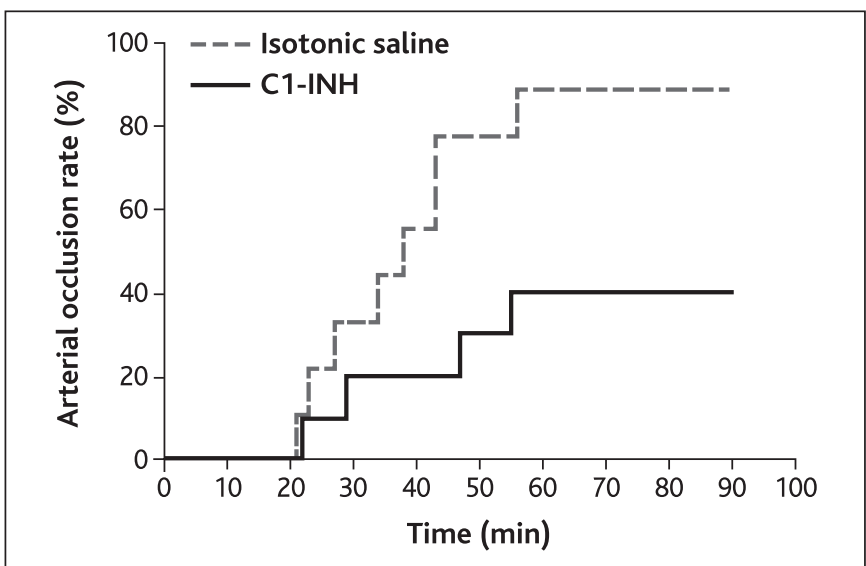

Figure 3: Effects of C1-esterase inhibitor (C1-INH) on arterial thrombosis in rabbits in vivo. A single dose of $800 \mathrm{IU} / \mathrm{kg} \mathrm{C1-INH}$ or an equal volume of isotonic saline was administered to rabbits followed by induction of arterial occlusion via $\mathrm{FeCl} 3$ in each arteria femoralis. Occlusion rate was calculated as percentage distribution of arteries showing full occlusion over time. 49.6-fold increase in C1-INH activity. In comparison, volume-adjusted treatment with isotonic saline resulted in a dilution effect observed as a reduction of C1-INH activity levels from $32 \%$ to $21 \%$ of endogenous normal levels.

Measurements of FXIa and FXIIa activities demonstrated the pharmacodynamic activity of human plasma-derived C1-INH in rabbits. Administration of cumulative doses of C1-INH to CHB rabbits resulted in a dose-dependent inhibition of FXIa and FXIIa activity compared with isotonic saline treatment ( Figure 1C). The inhibition was statistically significant, reaching levels of $78 \%$ $(\mathrm{p}<0.0001)$ of isotonic saline for FXIa and $66 \%(\mathrm{p}=0.0024)$ of isotonic saline for FXIIa at a dose of $400 \mathrm{IU} / \mathrm{kg}$, as well as $62 \%$ $(\mathrm{p}<0.0001)$ for FXIa and 59\% $(\mathrm{p}<0.0001)$ for FXIIa at a dose of $800 \mathrm{IU} / \mathrm{kg}$ (analysis of covariance of log-transformed data).

\section{Assessment of the prothrombotic potential of C1-INH in vivo}

As shown in $>$ Figure $2 \mathrm{~A}$ and $\mathrm{B}$, treatment of NZW rabbits with isotonic saline or C1-INH at doses up to $800 \mathrm{IU} / \mathrm{kg}$ following 30 min of venous stasis, did not induce any thrombus formation. In contrast, i.v. administration of Feiba, which was used as a positive control, resulted in a dose-dependent increase in thrombus formation reaching statistical significance $(\mathrm{p}<0.05)$ at doses of 25 to $100 \mathrm{IU} / \mathrm{kg}$ for thrombus score and at $100 \mathrm{IU} / \mathrm{kg}$ for thrombus wet weight.

Prolongation of venous stasis time to $3 \mathrm{~h}$ led to non-occlusive thrombus formation, even in animals treated with isotonic saline (23.3-106.1 mg thrombus wet weight). Even under these experimental conditions, administration of $\mathrm{C} 1-\mathrm{INH}$ at a high dose (i.e. $800 \mathrm{IU} / \mathrm{kg}$ ) did not result in any potentiation of venous thrombus formation ( Figure 2C). The mean thrombus wet weight was slightly but not statistically significantly lower after C1-INH administration $(47.2 \mathrm{mg}$ ) compared with isotonic saline $(66.0 \mathrm{mg})$.

Since the modified Wessler models applied above only address potential prothrombotic activity of C1-INH during venous stasis, its effect was further assessed using a rabbit model of $\mathrm{FeCl}_{3}$-induced arterial thrombosis. Interestingly, treatment of $\mathrm{CHB}$ rabbits with $800 \mathrm{IU} / \mathrm{kg} \mathrm{C1}-\mathrm{INH}$ led to an inhibition of arterial thrombus formation. Occlusion rates were up to 2.2-fold lower upon $\mathrm{C} 1-\mathrm{INH}$ treatment compared with isotonic saline, suggesting a rather antithrombotic role for C1-INH under these experimental conditions ( $\triangleright$ Figure 3; $\mathrm{p}=0.08$ for the log-rank test applied to mean time until occlusion of both arteries per animal).

\section{In vitro assessment of C1-INH effects on coagulation}

\section{Effects of C1-INH on activated partial thromboplastin time and prothrombin time}

Plasma from rabbits treated with cumulative C1-INH doses up to $800 \mathrm{IU} / \mathrm{kg}$ showed an increased aPTT from 21 seconds (sec) at pre-dose to $84 \mathrm{sec}$ at $400 \mathrm{IU} / \mathrm{kg} \mathrm{C1-INH}$. At $800 \mathrm{IU} / \mathrm{kg}$, an aPTT of $92 \mathrm{sec}$ could only be measured in one animal, while the aPTTs for the remaining animals were above the cut-off value of $160 \mathrm{sec}$. 
Therefore, the aPTT was set to $160 \mathrm{sec}$ for these animals ( $>$ Figure $4 \mathrm{~A}$ ). The prolongation of aPTT following $\mathrm{C} 1-\mathrm{INH}$ treatment was statistically significant compared with isotonic saline for all cumulative doses: $100 \mathrm{IU} / \mathrm{kg}(\mathrm{p}=0.035), 400 \mathrm{IU} / \mathrm{kg}(\mathrm{p}<0.001)$, and 800 $\mathrm{IU} / \mathrm{kg}(\mathrm{p}<0.001)$ (Wilcoxon test) and corresponding to the initial in vitro spike experiments (Suppl. Figure 1C, available online at www.thrombosis-online.com). No relevant effect of $\mathrm{C} 1-\mathrm{INH}$ treatment was observed on PT (data not shown) which ranged between $9.9 \mathrm{sec}$ and $10.3 \mathrm{sec}$ (mean values), with differences between
C1-INH and isotonic saline treatments smaller than $0.15 \mathrm{sec}$ at all doses ( $p>0.5$; analysis of covariance). These values were also in line with results obtained in the in vitro spike assay (Suppl. Figure $1 \mathrm{D}$, available online at www.thrombosis-online.com).

\section{Effects of C1-INH on thrombin generation}

Administration of up to $800 \mathrm{IU} / \mathrm{kg} \mathrm{C1}$-INH to rabbits revealed inhibitory effects of $\mathrm{C} 1-\mathrm{INH}$ on thrombin generation after intrinsic
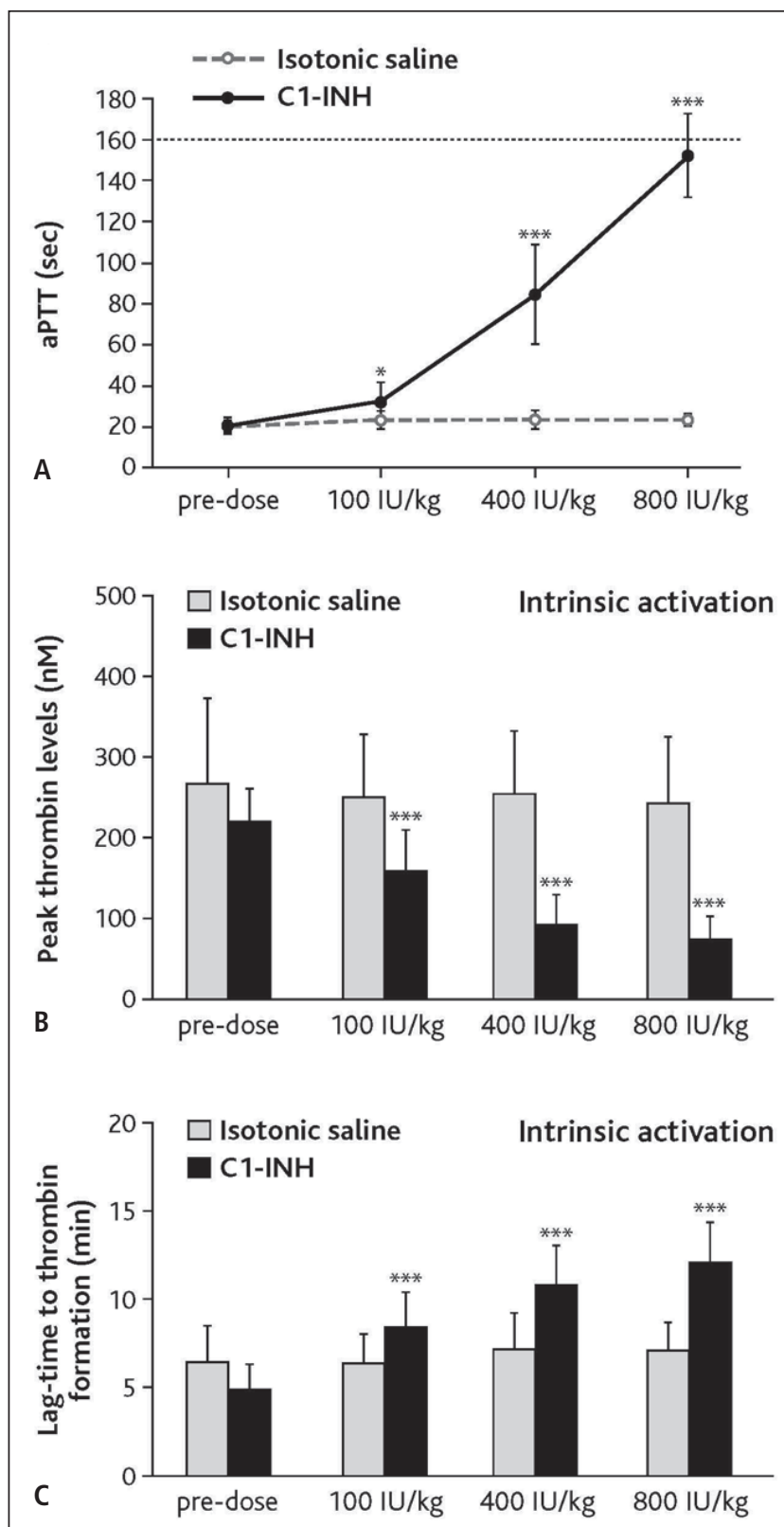

Figure 4: Effects of C1-esterase inhibitor (C1-INH) on activated partial thromboplastin time (aPTT) and thrombin generation in rabbits. Rabbits were injected with cumulative doses of C1-INH or equal volumes of isotonic saline and blood samples were drawn. A) APTT was measured following intrinsic activation (cut-off at $160 \mathrm{sec}$ ). Dots show means \pm SD. B-C) Peak thrombin levels (B) and lag-time to thrombin formation (C) were
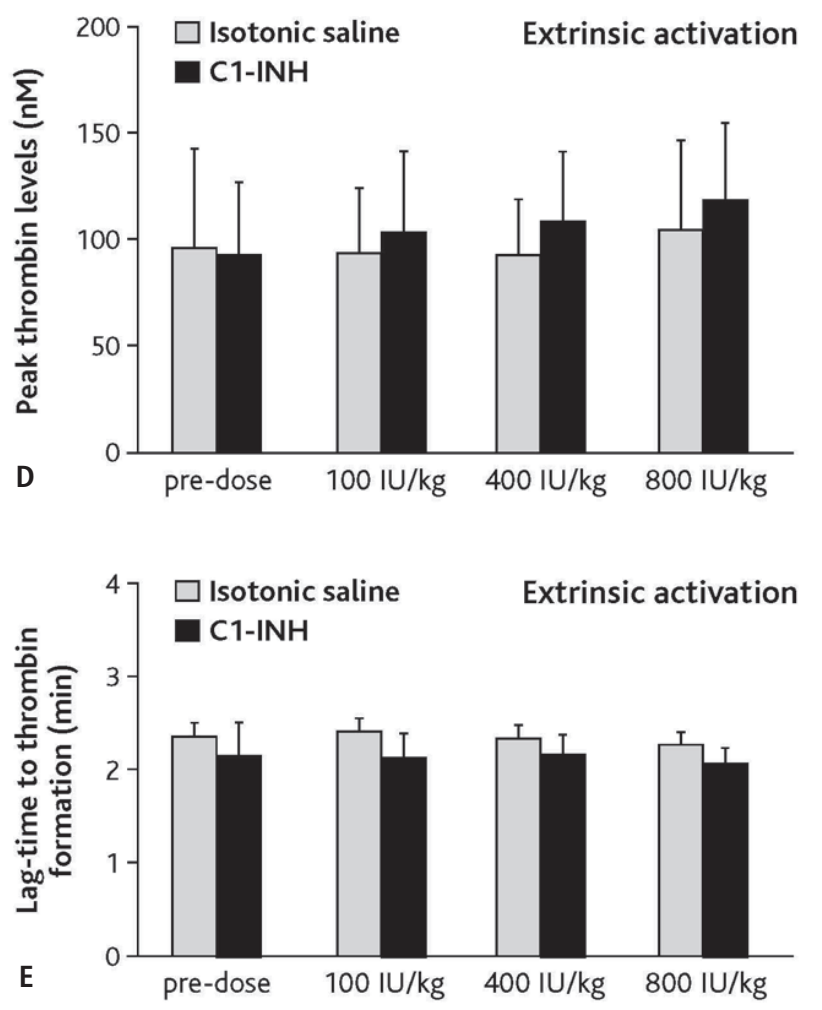

measured by calibrated thrombography upon intrinsic activation. For A-C: ${ }^{*} \mathrm{P}=0.035,{ }^{* *} \mathrm{P}<0.001$. Peak thrombin levels (D) and lag-time to thrombin formation (E) were measured by calibrated thrombography upon extrinsic activation. All data are statistically not significant with $P \geq 0.05$. For $B-D$ : Bars show means \pm SD. 
activation, reflected by changes in peak thrombin levels and lagtime ( Figure 4B and C). Compared with isotonic saline, peak thrombin levels were significantly reduced $(\mathrm{p}<0.001)$ after treatment with C1-INH by $29 \%(100 \mathrm{IU} / \mathrm{kg}), 61 \%(400 \mathrm{IU} / \mathrm{kg})$, and $66 \%(800 \mathrm{IU} / \mathrm{kg})$ (analysis of covariance of log-transformed data for all TGA parameters; Figure 4B). Lag-time was significantly prolonged $(\mathrm{p}<0.001)$ by 1.5 -fold $(100 \mathrm{IU} / \mathrm{kg} \mathrm{C} 1$-INH), 1.8 -fold (400 IU/kg C1-INH), and 2.0-fold (800 IU/kg C1-INH) compared with isotonic saline treatment ( Figure $4 \mathrm{C}$ ). In contrast, a very mild effect in the opposite direction was seen on peak thrombin levels and lag-time upon C1-INH treatment following extrinsic activation. The effect had borderline significance at some doses (peak thrombin levels increased by $16 \%$ at $800 \mathrm{IU} / \mathrm{kg} \mathrm{C1}-\mathrm{INH}$ and lag-time decreased by $6 \%$ at $100 \mathrm{IU} / \mathrm{kg}$ and $800 \mathrm{IU} / \mathrm{kg} \mathrm{C1-INH}$, compared with isotonic saline; $\mathrm{p}=0.05$ in each case; $>$ Figure $4 \mathrm{D}$ and E). ETP (measured as AUC) was not significantly affected by C1-INH treatment after intrinsic or extrinsic activation (differences between $\mathrm{C} 1-\mathrm{INH}$ and isotonic saline treatment were within $\pm 8 \%$; $>0.08$ for all doses; data not shown).

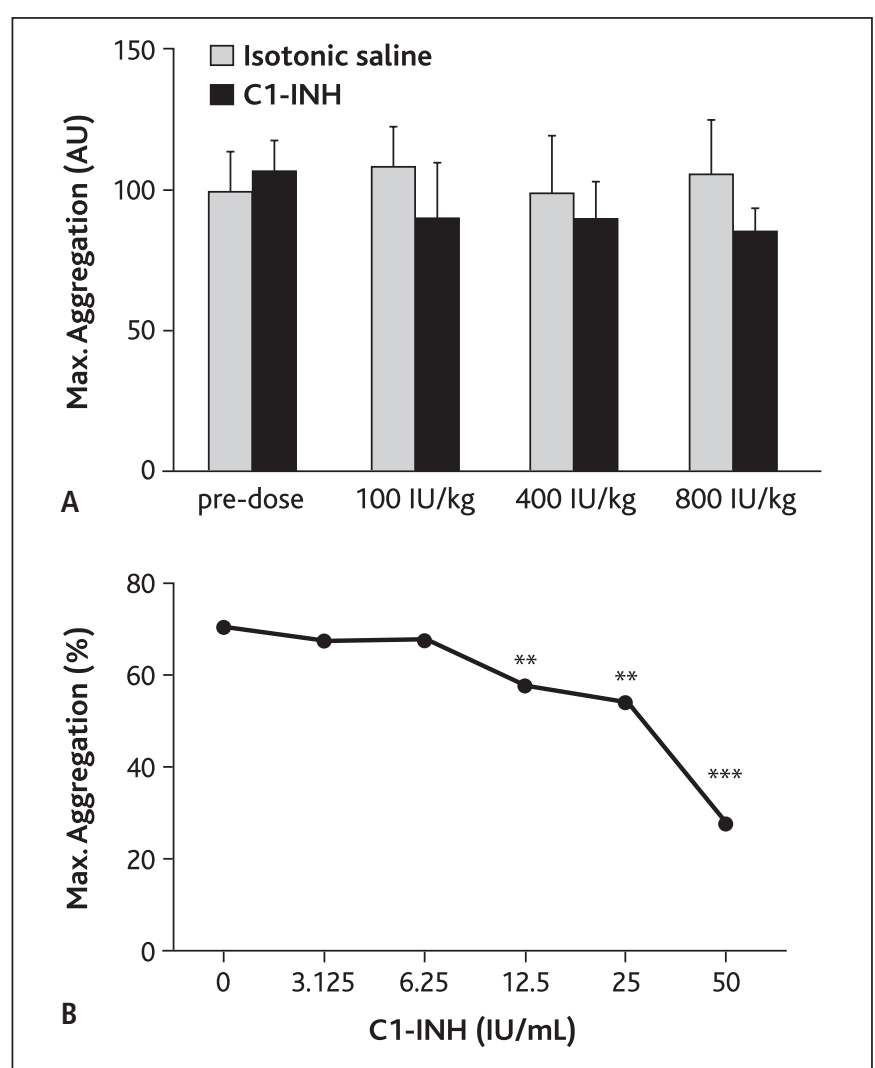

Figure 5: Effects of C1-esterase inhibitor (C1-INH) on platelet aggregation in rabbits. A) Rabbits were injected with cumulative doses of C1-INH or equal volumes of isotonic saline and blood samples were drawn. Maximum aggregation was measured upon collagen addition, using impedance aggregometry. Bars show means $\pm \mathrm{SD}$. AU=arbitrary units. B) Washed platelets from rabbit blood were spiked with C1-INH and platelet aggregation was induced by thrombin. Maximum aggregation was expressed as percentage of aggregated sample volume. Dots show means. ${ }^{* *} \mathrm{P}<0.01,{ }^{* * *} \mathrm{P}<0.0001$.

\section{Effects of C1-INH on platelet aggregation}

To elucidate C1-INH-mediated effects on platelet function, ADP or collagen was applied to blood samples drawn from C1-INH or isotonic saline treated rabbits in order to induce platelet aggregation. C1-INH administration of doses up to $800 \mathrm{IU} / \mathrm{kg}$ showed only a slight trend towards inhibitory effects on maximum platelet aggregation in the presence of collagen, although this was in a dose-independent manner and statistically not significant $(>$ Figure $5 \mathrm{~A}$ ). Platelet aggregation was not significantly affected by C1-INH treatment upon ADP induction (increase of AUC between $1 \%$ and $23 \%$ compared with isotonic saline; $p>0.3$; data not shown).

In a thrombin-induced in vitro assay of platelet aggregation ( Figure 5B), platelet concentrate was spiked with C1-INH at doses up to $50 \mathrm{IU} / \mathrm{ml}$ (translating to an in vivo dose of $1600 \mathrm{IU} / \mathrm{kg}$ ) and a dose-dependent decline in thrombin-induced maximum platelet aggregation was observed $(\mathrm{p}=0.0031, \mathrm{p}=0.0024$, and $\mathrm{p}<0.0001$ at $12.5 \mathrm{IU} / \mathrm{ml}, 25 \mathrm{IU} / \mathrm{ml}$, and $50 \mathrm{IU} / \mathrm{ml}$, respectively, compared to isotonic saline; analysis of variance).

\section{Effects of C1-INH on thrombus formation and fibrinolysis using thromboelastography}

Upon intrinsic activation of the coagulation cascade (INTEM test), CT and CFT increased in a dose-dependent manner between $10 \%$ and $23 \%$ (CT), and $13 \%$ and $29 \%$ (CFT) compared with isotonic saline, at $\mathrm{C} 1-\mathrm{INH}$ doses of $100 \mathrm{IU} / \mathrm{kg}$ and $800 \mathrm{IU} / \mathrm{kg}$, respectively (data not shown). The effects at $400 \mathrm{IU} / \mathrm{kg} \mathrm{C1}-\mathrm{INH}$ for CT $(\mathrm{p}=0.037)$ and at $800 \mathrm{IU} / \mathrm{kg} \mathrm{C1-INH}$ for CT and CFT $(p=0.013$ and $p=0.034$, respectively) were statistically significant (analysis of covariance of log-transformed data). MCF was not affected by $\mathrm{C} 1-\mathrm{INH}$ treatment and differed within a $2.3 \%$ range from isotonic saline levels at all doses tested (data not shown).

After extrinsic activation (EXTEM test), CFT increased by $7 \%$ at $400 \mathrm{IU} / \mathrm{kg}(\mathrm{p}=0.46)$ and $17 \%$ at $800 \mathrm{IU} / \mathrm{kg}(\mathrm{p}=0.08) \mathrm{C} 1-\mathrm{INH}$ administration compared with isotonic saline, while CT and MCF remained unaffected, showing differences in the range of 3.0\% (CT) and $0.6 \%(\mathrm{MCF})$ compared with isotonic saline levels at all doses ( $p>0.5$ ) (data not shown).

In addition, the NATEM test was used as one of the most sensitive methods assessing effects on the coagulation cascade. Here, in the absence of extrinsic or intrinsic activation, recalcification resulted in a prolongation of CT and CFT upon C1-INH administration. CT was prolonged by $21 \%$ at $100 \mathrm{IU} / \mathrm{kg}(\mathrm{p}=0.13), 42 \%$ at $400 \mathrm{IU} / \mathrm{kg}(\mathrm{p}=0.03)$, and $92 \%$ at $800 \mathrm{IU} / \mathrm{kg}(\mathrm{p}<0.0001)$ compared with isotonic saline administration (analysis of covariance of logtransformed data; $>$ Figure 6A). Median CFT was prolonged by $40 \%$ at $100 \mathrm{IU} / \mathrm{kg}(\mathrm{p}=0.03), 100 \%$ at $400 \mathrm{IU} / \mathrm{kg}(\mathrm{p}<0.001)$, and more than $100 \%$ at $800 \mathrm{IU} / \mathrm{kg}(\mathrm{p}=0.006$; log-rank test $)(>$ Figure $6 \mathrm{~B})$.

Measurements of LI60 following induction of clot lysis by addition of tPA, in order to assess potential inhibitory effects of $\mathrm{C} 1-\mathrm{INH}$ on fibrinolysis, revealed no indication of antifibrinolytic 
activity of C1-INH ( $>$ Figure 7; p >0.2 at all doses; analysis of covariance of log-transformed data).

\section{Effects of C1-INH on TAT and F1+2 levels}

After the administration of $800 \mathrm{IU} / \mathrm{kg} \mathrm{C1-INH}$ to rabbits, no relevant changes in the TAT and F1+2 levels were observed compared to isotonic saline treatment (data not shown).

\section{Discussion}

Overall, $\mathrm{C} 1-\mathrm{INH}$ replacement therapy has been recognized as a well-established, effective, and safe treatment for HAE acute attacks for over 20 years as well as in prophylaxis. However, adverse events reported in association with $\mathrm{C} 1-\mathrm{INH}$ treatment include risk of thromboembolic complications upon administration at both high and recommended doses $(8,9)$. Recently, few clinical and preclinical reports have provided contradictory evidence on the possible prothrombotic potential of C1-INH treatment (11, $13,14)$. However, no causative mechanism has been demonstrated so far and remains elusive. Therefore, our study aimed to provide further insight into the involvement of $\mathrm{C} 1-\mathrm{INH}$ in coagulatory functions and its role in thromboembolic events.

To this end, the rabbit was chosen as a suitable experimental model, providing high sensitivity due to its high endogenous levels of coagulation factors compared with humans or other experimental species (26). In our study, the pharmacokinetic behaviour of $\mathrm{C} 1-\mathrm{INH}$ in rabbits was in agreement with previous observations in rabbits (27), and $\mathrm{C} 1-\mathrm{INH}$ showed pharmacodynamic efficacy, as demonstrated by a dose-dependent inhibition of FXIa and FXIIa activities ( $>$ Figure 1). Based on additional in vitro experiments, the dose-response of this effect was similar between human- and rabbit-derived plasma although more pronounced for human plasma in the case of FXIa inhibition (Suppl. Figure 1, available online at www.thrombosis-online.com). On the other hand, the increased effect on aPTT seen in rabbit plasma ( $>$ Figure 1C) may point to a stronger inhibitory effect of of C1-INH on rabbit plasma kallikrein compared to human kallikrein. Via Western blotting using C1-INH it was found that inhibition of contact system activation was similar between human and rabbit plasma (Suppl. Figure 2, available online at www. thrombosis-online.com). Furthermore, literature is available suggesting that human $\mathrm{C} 1-\mathrm{INH}$ has not just strong inhibitory potency on human complement proteases C1r, C1s and MASP-1, but also on rabbit $\mathrm{C} 1 \mathrm{~s}$, further supporting the rabbit as a pharmacologically relevant animal model to study the effects of human C1-INH (28). However, it remains to be elucidated whether human C1-INH is equally potent in rabbits as it is in humans. Therefore, the potential differences in the contact system between human and rabbit, including the differences between the effects of C1-INH on FXIa inhibition and aPTT or discrepancies between FXIa and PT baseline levels as seen in this study, have to be kept in mind when interpreting and translating data from rabbit models to humans.

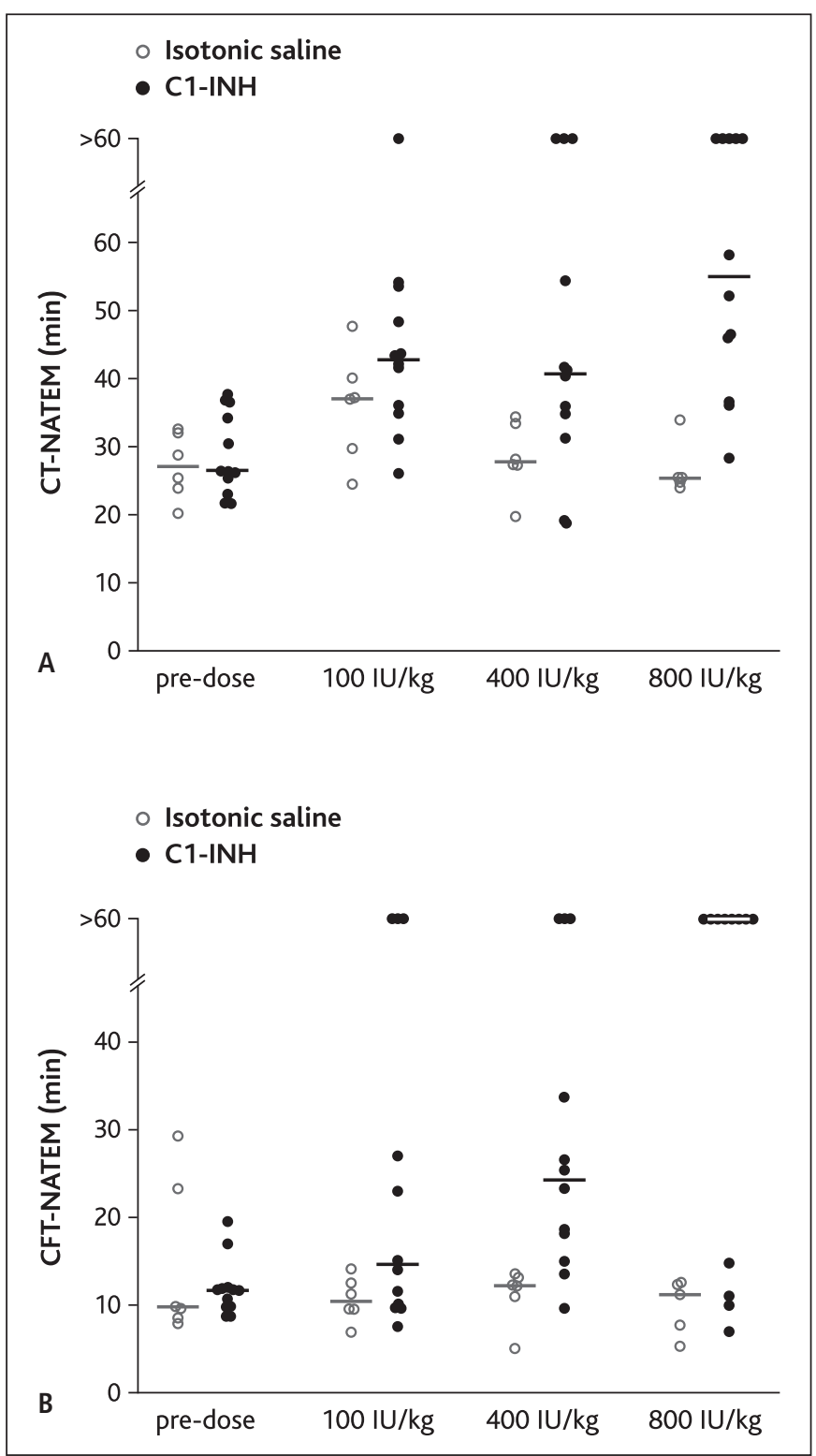

Figure 6: Effects of C1-esterase inhibitor (C1-INH) on thrombus formation in rabbits using thromboelastography. Clotting time (CT) (A) and clot formation time (CFT) (B) were measured after recalcification only (NATEM) of citrated whole blood from rabbits treated with cumulative doses of C1-INH or equal volumes of isotonic saline. Horizontal lines correspond to medians.

At present, a potential procoagulatory role of $\mathrm{C} 1-\mathrm{INH}$ is being discussed. An underlying mechanism leading to this class of adverse events observed has not been demonstrated; however, potential antifibrinolytic effects of C1-INH have been considered. Due to its ability to inhibit the function of FXIa, FXIIa, and kallikrein, $\mathrm{C} 1-\mathrm{INH}$ could potentially elicit those procoagulatory events by interfering with downstream cascades such as the fibrinolytic pathway ( Figure 8A). During fibrinolysis, plasmin is generated by plasminogen upon the action of tPA and urokinase-like plasminogen activator (uPA); plasmin subsequently catalyses the 


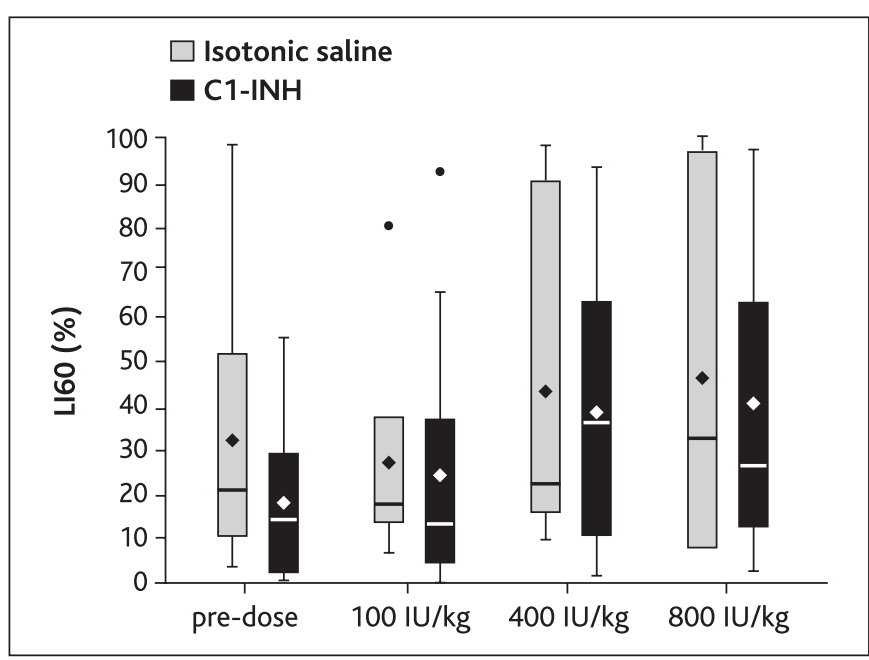

Figure 7: Effects of C1-esterase inhibitor (C1-INH) on fibrinolysis in rabbits. CHB rabbits were injected with cumulative doses of C1-INH or equal volumes of isotonic saline and blood samples were drawn. Fibrinolysis was induced by addition of TPA and upon extrinsic activation. Lysis index 60 (LI60) was measured using thromboelastography. Bottom and top of the box represent the 25th and 75th percentile, respectively, the band within the box represents the median, the diamond symbol represents the mean, and the low and high ends of the whiskers represent the lowest datum still within 1.5 interquartile range (IQR) of the lower quartile, and the highest datum still within 1.5 IQR of the upper quartile, respectively.

degradation of fibrin clots (29). C1-INH could interfere with plasmin production in multiple ways: directly, by inhibiting the activity of tPA (30) or the cleavage of plasminogen by FXIIa (32), or indirectly, by inhibiting the activity of kallikrein. The latter could lead to decreased urokinase and subsequently reduced plasminogen activation (31), as well as to decreased tPA levels due to reduced bradykinin production downstream of kallikrein (32). The contribution of C1-INH to tPA inhibition seems to depend on the active levels of plasminogen activator inhibitor-1 (PAI-1), and C1-INH may inhibit as little as $5 \%$ of plasma tPA under certain active PAI-1 concentrations (30). Since active PAI-1 levels can vary between healthy individuals and certain patient populations (30), different subjects may exhibit varying sensitivities to the potential antifibrinolytic effects of C1-INH. However, C1-INH seems to play only a limited role in $\mathrm{PA}$ inhibition. Clinical data has demonstrated that the levels of tPA and uPA remained normal during both remission and acute attacks of HAE patients (33) and increased C1-INH-tPA complexes were only observed in presence of high tPA levels in the circulation $(3,34)$.

Furthermore, it could be speculated from the literature that C1-INH could potentially elicit additional procoagulatory effects by indirectly increasing platelet activation and/or fibrin clot formation ( Figure 8A). Reduced bradykinin levels, due to C1-INH-mediated inhibition of kallikrein, could likely decrease the release of prostaglandin I2 and nitric oxide from endothelial cells, which usually exert platelet inhibitory effects, thus decreasing the barrier for platelet activation $(35,36)$. However, this hypothesis was not further investigated or proven as part of the present study.
In addition, cleaved kinin-free kininogen was shown to compete with fibrinogen for deposition on negatively-charged surfaces, neutrophils, and platelets (31). Therefore, reduced cleaved kininfree kininogen levels, due to inhibition of FXIIa by $\mathrm{C} 1-\mathrm{INH}$, may potentially lead to reduced displacement of fibrinogen and increased fibrin formation.

Nevertheless, despite the theoretical impact of the potential procoagulatory effects of $\mathrm{C} 1-\mathrm{INH}$ described above, in the present work no such findings underlining this hypothesis were observed. Thus, our study clearly suggests no prothrombotic risk associated with C1-INH treatment in rabbits, even at supratherapeutic doses.

In the current study, in vivo models of thrombogenicity were employed to assess the prothrombotic potential of C1-INH, as a sensitive readout of the interplay between blood cells, cell membranes, vascular wall, blood flow conditions, and local or systemic conditions such as hypoxia or acidosis. The modified Wessler test in rabbits is a well-established model of acute and prolonged venous stasis, mimicking major aspects of deep-vein thrombosis in humans. Following venous stasis, C1-INH doses up to $800 \mathrm{IU} / \mathrm{kg}$ did not result in any potentiation of thrombus formation ( $>$ Figure 2). Interestingly, the additional application of a chemically-induced arterial thrombosis model in rabbits revealed anticoagulatory properties for C1-INH, with doses of $800 \mathrm{IU} / \mathrm{kg}$ C1-INH resulting in a 2.2-fold reduction of total arterial occlusion compared with isotonic saline treatment ( $>$ Figure 3 ).

The in vivo observations were further supported by a variety of in vitro assays assessing the impact of $\mathrm{Cl}$-INH treatment on the contact activation system, thrombin generation, platelet aggregation, and fibrinolysis. In contrast to the theoretical potential of $\mathrm{C} 1-\mathrm{INH}$ to enhance clot formation as described above, a prolongation of CT, CFT, aPTT and lag-time of thrombin formation, and a decrease in peak thrombin levels were observed in the presence of C1-INH upon intrinsic activation of thrombin generation, pointing towards an anticoagulatory effect for this treatment ( Figure 4A-C and $>$ Figure 6). No effect of C1-INH was observed on PT (Suppl. Figure 1D, available online at www.thrombo sis-online.com) or on thrombin generation following extrinsic activation ( Figure 4D-E).

Our findings showing a potential anticoagulatory role for C1-INH are not surprising considering the multiple functions of this protein within the contact activation and complement cascades and the complex interplay among these pathways.

Firstly, any interference of $\mathrm{Cl}$-INH with the contact activation system, i. e. through inhibition of FXIIa, FXIa, or kallikrein, could modulate vascular biology by decreasing thrombin generation (3) ( Figure 8B), a finding that was observed in the present study following intrinsic activation of thrombin generation as demonstrated in $>$ Figure $4 \mathrm{~B}-\mathrm{C}$.

In addition, the observed inhibition of platelet aggregation when thrombin was used as platelet agonist ( $>$ Figure 5) in the presence of $\mathrm{C} 1-\mathrm{INH}$ further argues against a prothrombotic role for this treatment. These findings are partly in line with results from Copolla et al. who hypothesised a negative regulating role of C1-INH in platelet aggregation $(37,38)$. In general, platelet activation is positively regulated by thrombin, collagen, and thromb- 
oxane A2 (TXA2) (37). C1-INH could interfere with this process either directly, by binding to thrombin $(39,40)$ and collagen $(41)$, or indirectly by downregulating bradykinin levels, leading to reduced TXA2 production via the arachidonic acid pathway (42-44). In addition, reduced FXIIa and kallikrein activity, due to
C1-INH inhibition, may potentially affect neutrophil-platelet interactions $(45,46)$.

The potential interaction of $\mathrm{C} 1-\mathrm{INH}$ with thrombin may consequently enhance the fibrinolytic system, considering the inhibitory effects of thrombin on fibrinolysis (47) and the decrease in

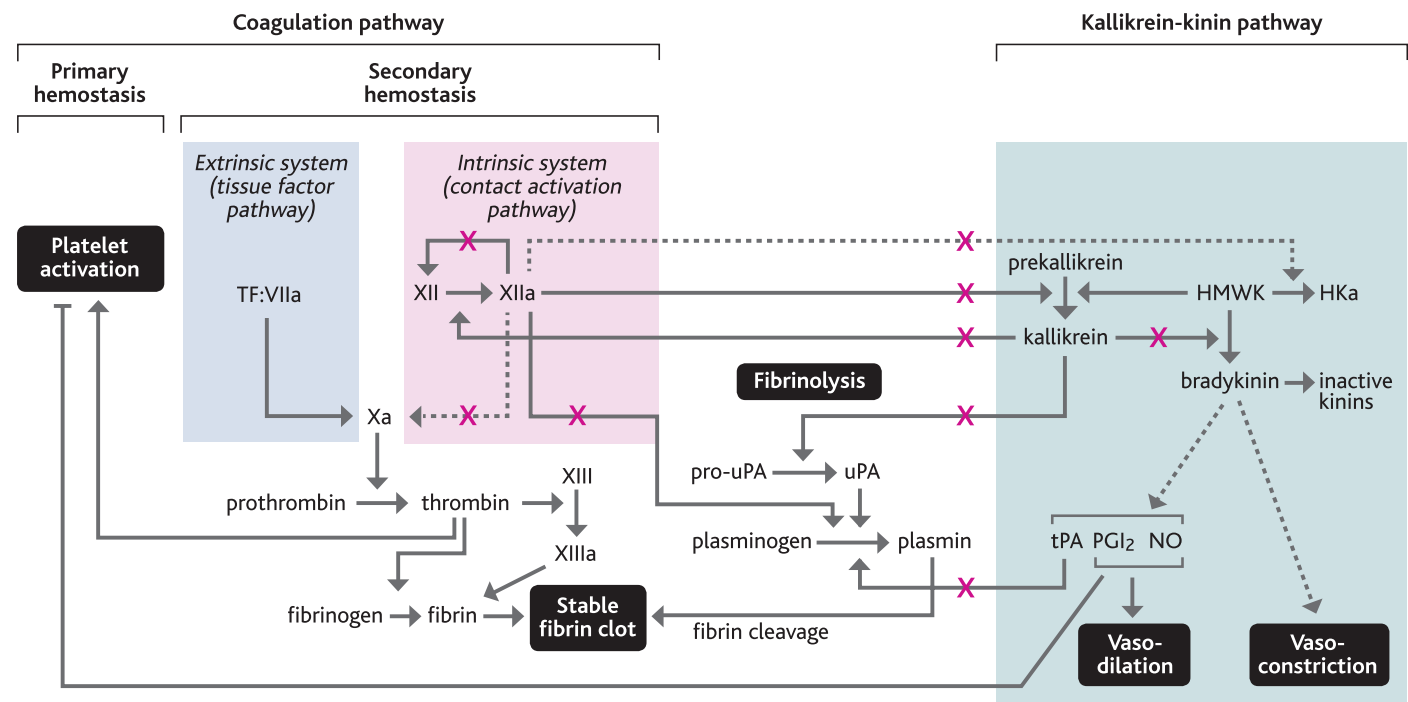

A

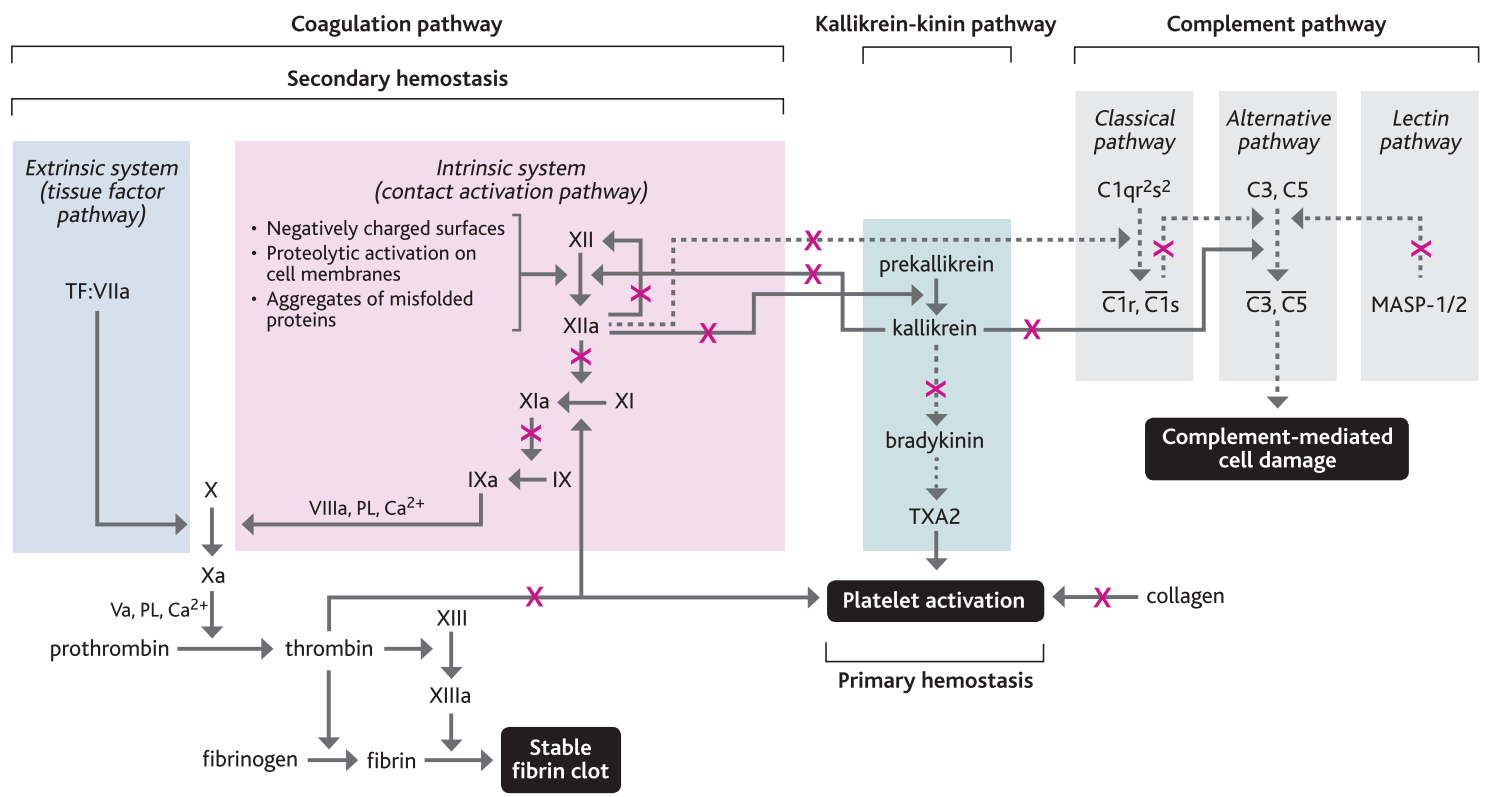

Figure 8: Potential pro (A) and anticoagulatory (B) effects of C1esterase inhibitor (C1-INH) function. C1-INH can potentially elicit procoagulatory effects $(A)$, by inhibiting fibrinolysis or increasing platelet activation, but also anticoagulatory effects (B), by inhibiting thrombin formation, platelet activation, or the function of complement pathway. Dotted arrows indicate indirect actions and continuous arrows indicate direct actions. Red Xs indicate inhibition by C1-INH. Ca=calcium; coagulation factors Va, VIIIa,
IX/IXa, X/Xa, XI/XIa, XII/XIIa, XIII/XIIIa; HKa=cleaved kinin-free kininogen; $\mathrm{HMWK}=$ high-molecular weight kininogen; $\mathrm{MASP}=$ mannose-binding lectinassociated serine protease; $\mathrm{NO}=$ nitric oxide; $\mathrm{PGI}=$ prostaglandin 12; $\mathrm{PL}=$ phospholipids; pro-uPA=pro-urokinase-type plasminogen activator; TF:VIla=TF complex with factor VIla; tPA=tissue plasminogen activator; TXA2=thromboxane A2; uPA=urokinase-type plasminogen activator. 
thrombin generation upon C1-INH action. However, no relevant changes in fibrinolytic activity were observed in this study upon Cl-INH treatment $(\nabla$ Figure 7$)$.

Furthermore, C1-INH could potentially exert anticoagulatory effects via its action on the complement system ( Figure 8B). $\mathrm{C} 1-\mathrm{INH}$ can interfere with the complement system directly, by inhibiting the activity of the serine proteases $\mathrm{Cls}$ and $\mathrm{Cl}$, as well as of MASP-1 (mannose-binding lectin-associated serine protease) and MASP-2, but also indirectly, by blocking FXII autoactivation and kallikrein. Upon cleavage of FXIla by kallikrein, the FXIIa â-fragment is produced which can transform the macromolecular $\mathrm{Clqr}^{2} \mathrm{~s}^{2}$ complex into enzymatically active C1r and C1s $(48,49)$. Moreover, kallikrein can directly activate C3 and C5. Therefore, inhibition of FXII autoactivation and kallikrein by $\mathrm{C} 1-\mathrm{INH}$ could lead to the downregulation of the classical, lectin, and alternative pathways of the complement system and may consequently suppress the stimulation of downstream procoagulatory events triggered by complement fixation on cell surfaces (50) or anaphylatoxin (C3a and C5a)-mediated inflammatory responses (51).

Overall, C1-INH administration at supratherapeutic doses in rabbits revealed an antithrombotic effect for this treatment. However, it should be taken into consideration that the adverse thromboembolic events reported previously have not been observed under healthy conditions but against a background of capillary leakage syndrome or heart insufficiencies, which are off-label indications for C1-INH. In addition, it cannot be neglected that $\mathrm{C} 1-\mathrm{INH}$ activity can be affected by co-treatments or by the status or severity of HAE. In the first case it has been demonstrated that co-treatment with glycosaminoglycans such as Heparins can increase C1-INH activity $(52,53)$ and the mean half-life of therapeutically administered C1-INH has been shown to vary from 33

\section{What is known about this topic?}

- C1-INH is a potent inhibitor of the complement and contact activation systems, and its deficiency can lead to the manifestation of hereditary angioedema. Replacement therapy with human plasma-derived C1-INH is an efficacious and safe treatment for this disease.

- However, thrombotic events have been associated with the use of C1-INH at recommended or off-label, high doses.

\section{What does this paper add?}

- High-dose C1-INH administration to rabbits did not potentiate venous thrombosis, and interestingly inhibited arterial thrombosis.

- Decreased thrombin generation and platelet aggregation, as well as prolonged activated partial thromboplastin time, clotting time, and clot formation time were observed upon high dose administration of C1-INH.

- C1-INH administration to healthy rabbits at high doses seems to have anticoagulatory and antithrombotic effects, rather than a prothrombotic potential. $\mathrm{h}$ up to $48 \mathrm{~h}$ for patients with severe HAE and patients with moderate HAE, respectively (54).

In summary, assessment of the prothrombotic risk of $\mathrm{C} 1-\mathrm{INH}$ treatment in rabbits revealed a rather anticoagulatory role for C1-INH in this study. Venous thrombosis was not potentiated and arterial thrombosis was inhibited upon C1-INH administration at supratherapeutic doses. Inhibition of the contact activation system, reduced thrombin generation, and reduced platelet aggregation were observed in blood samples of C1-INH treated animals, further supporting the anticoagulatory potential of $\mathrm{C} 1-\mathrm{INH}$. Furthermore, there was no apparent $\mathrm{C} 1$-INH-mediated inhibition of fibrinolysis. Nevertheless, as the present study was conducted in healthy rabbits, future investigations of the prothrombotic risk of C1-INH are warranted in various clinical backgrounds reflecting the potentially complex influences of underlying disease states in patients.

\section{Acknowledgments}

The authors would like to thank Franz Kaspereit, Wilfried Krege, Bärbel Dörr, Sabrina Schenk, and Patrick Letmade (all CSL Behring $\mathrm{GmbH}$ ) for their excellent technical assistance, and Dr. Ioanna Bethani at Trilogy Writing \& Consulting (Frankfurt am Main, Germany) for assistance in preparing the manuscript. Work on inhibition of HMWK cleavage was performed using funding provided by Vetenskapsrådet (K2013-65X-21462-04-5), German Research Society (SFBs $841 \&$ 877) and European Research Council grant (ERC-StG-2012-311575_F-12). CSL Behring sponsored the Open Access fee for this manuscript.

\section{Conflicts of interest}

D. Schürmann, E. Herzog, E. Raquet, M. W. Nolte, F. May, J. Müller-Cohrs, G. Dickneite, and I. Pragst are employees of CSL Behring GmbH. J. Björkqvist declares no conflicts of interest.

\section{References}

1. Bock SC, Skriver K, Nielsen E, et al. Human C1 inhibitor: primary structure, cDNA cloning, and chromosomal localization. Biochemistry 1986; 25: 4292-4301.

2. Davis AE. The pathophysiology of hereditary angioedema. Clin Immunol 2005; 114: 3-9.

3. Caliezi C, Wuillemin WA, Zeerleder S, et al. C1-Esterase Inhibitor: an anti-inflammatory agent and its potential use in the treatment of diseases other than hereditary angioedema. Pharmacol Rev 2000; 52: 91-112.

4. Longhurst H, Cicardi M. Hereditary angio-oedema. Lancet 2012; 379: 474-481.

5. Bork K. Diagnosis and treatment of hereditary angioedema with normal $\mathrm{Cl}$ inhibitor. Poster presented at the 2012 AAAAI Annual Meeting, Orlando, Florida. Allergy Asthma Clin Immunol 2010; 6: 15.

6. Bork K, Korger G, Kreuz W. Review of the long-term safety of a human pasteurized C1 inhibitor concentrate. J Allergy Clin Immunol 2012; 129:2S: AB222. Cicardi M, Zingale LC, Zanichelli A, et al. The use of plasma-derived C1 inhibitor in the treatment of hereditary angioedema. Expert Opin Pharmacother 2007; 8: 3173-3181.

7. Berinert US Prescribing Information. Available at: http://labeling.cslbehring.com/PI/US/Berinert/EN/Berinert-Prescribing-Information.pdf. Accessed May 22, 2013.

8. Cinryze US Prescribing Information. Available at: http://www.cinryze.com/ pdfs/cinryze-prescribing-information.pdf. Accessed May 22, 2013. 
9. German Medical Profession's Drugs Committee. Severe thrombus formation of Berinert $^{\circ}$ HS. Deutsches Ärzteblatt 2000; 97: A-1016/B-864/C-812.

10. Horstick G, Berg O, Heimann A, et al. Application of C1-esterase inhibitor during reperfusion of ischemic myocardium: dose-related beneficial versus detrimental effects. Circulation 2001; 104: 3125-3131.

11. Pharmacology / Toxicology Review Memorandum. STN 125267 - C1 Esterase Inhibitor for the treatment of human angioedema (HAE). Buehler PW. Department of Health and Human Services Food and Drug Administration Center for Biologics Evaluation and Research. August, 2007. Available at: http://www.fda. gov/downloads/BiologicsBloodVaccines/BloodBloodProducts/ApprovedProducts/LicensedProductsBLAs/FractionatedPlasmaProducts/UCM229783.pdf. Accessed May 22, 2013.

12. Tassani P, Kunkel R, Richter JA, et al. Effect of C1-esterase-inhibitor on capillary leak and inflammatory response syndrome during arterial switch operations in neonates. J Cardiothorac Vasc Anesth 2001; 15: 469-473.

13. Ghandi PK, Gentry WM, Bottorff MB. Thrombotic events associated with $\mathrm{C} 1$ esterase inhibitor products in patients with hereditary angioedema: Investigation from the United States Food and Drug Administration Adverse Event Reporting System Database. Pharmacotherapy 2012; 32: 902-909.

14. Relan A, Bakhtiari K, van Amersfoort ES, et al. Recombinant C1-inhibitor. Effects on coagulation and fibrinolysis in patients with hereditary angioedema. Biodrugs 2012; 26: 43-52.

15. Cugno M, Cicardi M, Bottasso B, et al. Activation of the coagulation cascade in C1-inhibitor deficiencies. Blood 1997; 89: 3213-3218.

16. Heydenreich N, Nolte MW, Göb E, et al. C1-inhibitor protects from brain ischemia-reperfusion injury by combined antiinflammatory and antithrombotic mechanisms. Stroke 2012; 43: 2457-2467.

17. Hagedorn I, Schmidbauer S, Pleines I, et al. Factor XIIa inhibitor recombinant human albumin Infestin-4 abolishes occlusive arterial thrombus formation without affecting bleeding. Circulation 2010; 121: 1510-1517.

18. Schumacher WA, Seiler SE, Steinbacher TE, et al. Antithrombotic and hemostatic effects of a small molecule factor XIa inhibitor in rats. Eur J Pharmacol 2007; 570: 167-174.

19. Renné T, Pozgajová $M$, Grüner $S$, et al. Defective thrombus formation in mice lacking coagulation factor XII. J Exp Med 2005; 202: 271-281.

20. Rosen ED, Gailani D, Castellino FJ. FXI is essential for thrombus formation following $\mathrm{FeCl} 3$-induced injury of the carotid artery in the mouse. Thromb Haemost 2002; 87: 774-776.

21. Wessler S, Ward K, Ho C. Studies in intravascular coagulation. III. The pathogenesis of serum-induced venous thrombosis. J Clin Invest 1955; 34: 647-651.

22. Giles AR, Johnston M, Hoogendoorn $\mathrm{H}$, et al. The thrombogenicity of prothrombin complex concentrates: I. The relationship between in vitro characteristics and in vivo thrombogenicity in rabbits. Thromb Res 1980; 17: 353-366.

23. Reimann-Hunziger G. Über experimentelle Thrombose und ihre Behandlung mit Heparin. Schweiz Med Wschr 1944; 74: 66-69.

24. Kurz KD, Main BW, Sandusky GE. Rat model of arterial thrombosis induced by ferric chloride. Thromb Res 1990; 60: 269-280.

25. Karges HE, Funk KA, Ronneberger H. Activity of coagulation and fibrinolysis parameters in animals. Arzneimittelforschung 1994; 44: 793-797.

26. Minta JO. The role of sialic acid in the functional activity and the hepatic clearance of C1-INH. J Immunol 1981; 126: 245-249.

27. Buerke M, Schwertz H, Seitz W, et al. Novel small molecule inhibitor of C1s exerts cardioprotective effects in ischemia-reperfusion injury in rabbits. J Immunol 2001; 167: 5375-5380.

28. Schaller J, Gerber SS. The plasmin-antiplasmin system: structural and functional aspects. Cell Mol Life Sci 2011; 68: 785-801.

29. Chandler WL, Levy WC, Stratton JR. The circulatory regulation of TPA and UPA secretion, clearance, and inhibition during exercise and during the infusion of isoproterenol and phenylephrine. Circulation 1995; 92: 2984-2994.

30. Colman RW, Schmaier AH. Contact System: A vascular biology modulator with anticoagulant, profibrinolytic, antiadhesive, and proinflammatory attributes. Blood 1997; 90: 3819-3843.
31. Brown NJ, Gainer JV, Stein CM, et al. Bradykinin stimulates tissue plasminogen activator release in human vasculature. Hypertension 1999; 33: 1431-1435.

32. Cugno M, Hack CE, de Boer JP, et al. Generation of plasmin during acute attacks of hereditary angioedema. J Lab Clin Med 1993; 121: 38-43.

33. Huisman LGM, van Griensven JMT, Kluft C. On the role of C1-inhibitor as inhibitor of tissue-type plasminogen activator in human plasma. Thromb Haemost 1995; 73: 466-471.

34. Sainz IM, Pixley RA, Colman RW. Fifty years of research on the plasma kallikrein-kinin system: From protein structure and function to cell biology and in-vivo pathophysiology. Thromb Haemost 2007; 98: 77-83.

35. Brass LF. Thrombin and platelet activation. Chest 2003; 124: 18S-25S.

36. Coppola L, Tirelli A, Giunta R, et al. C1-inhibitor and platelet aggregation. Haematologica 1988; 73: 153-161.

37. Coppola L, Guastafierro S, Verrazzo G, et al. C1 inhibitor infusion modifies platelet activity in hereditary angioedema patients. Arch Pathol Lab Med 2002; 126: $842-845$

38. Caccia S, Castelli R, Maiocchi D, et al. Interaction of $\mathrm{C} 1$ inhibitor with thrombin on the endothelial surface. Blood Coagul Fibrinolysis 2011; 22: 571-575.

39. Cugno M, Bos I, Lubbers $\mathrm{Y}$, et al. In vitro interaction of $\mathrm{C} 1$-inhibitor with thrombin. Blood Coagul Fibrinolysis 2001; 12: 253-260.

40. Patston PA, Schapira M. Regulation of C1-inhibitor function by binding to type IV collagen and heparin. Biochem Biophys Res Commun 1997; 230: 597-601.

41. Gecse A, Kis B, Mezei Z, et al. The effect of bradykinin and substance P on the arachidonate cascade of platelets. Immunopharmacology 1996; 33: 167-170.

42. Crutchley DJ, Ryan JW, Ryan US, et al. Bradykinin-induced release of prostacyclin and thromboxanes from bovine pulmonary artery endothelial cells. Studies with lower homologs and calcium antagonists. Biochim Biophys Acta 1983; 751: 99-107.

43. Schrör K. Role of prostaglandins in the cardiovascular effects of bradykinin and angiotensin-converting enzyme inhibitors. J Cardiovasc Pharmacol 1992; 20: S68-73.

44. von Brühl ML, Stark K, Steinhart A, et al. Monocytes, neutrophils, and platelets cooperate to initiate and propagate venous thrombosis in mice in vivo. J Exp Med 2012; 209: 819-835.

45. Zarbock A, Polanowska-Grabowska RK, Ley K. Platelet-neutrophil-interactions: linking hemostasis and inflammation. Blood Rev 2007; 21: 99-111.

46. Mosnier LO, Bouma BN. Regulation of fibrinolysis by thrombin activatable fibrinolysis inhibitor, an unstable carboxypeptidase $B$ that unites the pathways of coagulation and fibrinolysis. Arterioscler Thromb Vasc Biol 2006; 26: 2445-2453.

47. Kaplan AP, Ghebrehiwet B. The plasma bradykinin-forming pathways and its interrelationships with complement. Mol Immunol 2010; 47: 2161-2169.

48. Schmaier AH. The elusive physiologic role of Factor XII. J Clin. Invest. 2008; 118: 3006-3009.

49. Carson SD, Johnson DR. Consecutive enzyme cascades: complement activation at the cell surface triggers increased tissue factor activity. Blood 1990; 76: 361-367.

50. Hartmann K, Henz BM, Krüger-Krasagakes S, et al. C3a and C5a stimulate chemotaxis of human mast cells. Blood 1997; 89: 2863-2870.

51. Wuillemin WA, te Velthuis H, Lubbers YT, et al. Potentiation of $\mathrm{C} 1$ inhibitor by glycosaminoglycans: dextran sulfate species are effective inhibitors of in vitro complement activation in plasma. J Immunol 1997; 159: 1953-1960.

52. Wuillemin WA, Eldering E, Citarella F, et al. Modulation of contact system proteases by glycosaminoglycans. Selective enhancement of the inhibition of factor XIa. J Biol Chem 1996; 271: 12913-12918.

53. Martinez-Saguer I, Rusicke E, Aygören-Pürsün E, et al. Pharmacokinetic analysis of human plasma-derived pasteurized C1-inhibitor concentrate in adults and children with hereditary angioedema: a prospective study. Transfusion 2010; 50: 354-360. 